\title{
Physics Behind the Climate Change
}

\author{
Jeevan Regmi \\ Department of Physics, Prithvi Narayan Campus, Pokhara
}

\begin{abstract}
There is an urgent need for science to inform society about the cost of failure to address the global warming. The challenges offered by global climate change have not been fully recognized by the public and decision making bodies. The severity of climate change has not been taken seriously. It is limited to declarations and propagandas only. Time has come to act globally.
\end{abstract}

Keywords: Energy balance, solar variation, global warming, greenhouse gases, deforestation, feedback, forcing agent

\section{INTRODUCTION:}

Climate change is a significant time variation in weather patterns occurring over periods ranging from decades to millions of years. Climate change may refer to a change in average weather conditions, or in the time variation of weather around longerterm average conditions.

\section{NATURAL CAUSES OF CLIMATE CHANGE}

The earth's climate is influenced and changed through natural causes like volcanic eruptions, ocean current, the earth's orbital changes and solar variations.

Volcanic eruptions - The volcanic eruptions throw out large volumes of sulphur dioxide $\left(\mathrm{SO}_{2}\right)$, water vapour, dust, and ash into the atmosphere. Large volumes of gases and ash can influence climatic patterns for years by increasing planetary reflectivity causing atmospheric cooling. Tiny particles called aerosols are produced by volcanoes which reflect solar energy back into space causing a cooling effect on the world. The greenhouse gas, carbon dioxide is also produced however the $\mathrm{CO}_{2}$ produced is insignificant when compared to emissions created by humans.

Ocean current - Ocean currents move vast amounts of heat across the planet. Winds push horizontally against the sea surface and drive ocean current patterns. Deep ocean circulation of cold water from the poles towards the equator and movement of warm water from the equator back towards the poles. Without this movement the poles would be colder and the equator warmer. The oceans play an important role in determining the atmospheric concentration of $\mathrm{CO}_{2}$. Changes in ocean circulation may affect the climate through the movement of $\mathrm{CO}_{2}$ into or out of the atmosphere.

Earth orbital changes - The earth is tilted at an angle of $23.5^{\circ}$ to the perpendicular plane of its orbital path. Changes in the tilt of the earth can lead to small but climatically important changes in the strength of the seasons, more tilt means warmer summers and colder winters; less tilt means cooler summers and milder winters.

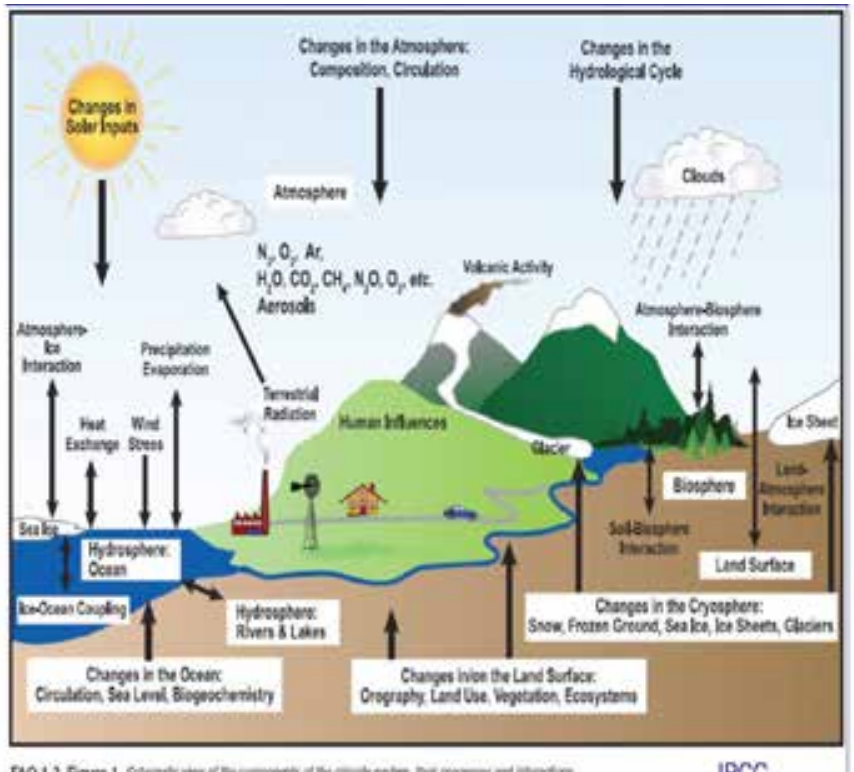

Solar variations -. Although the Sun's energy output appears constant from an everyday point of view, small changes over an extended period of time can lead to climate changes. As the sun is the fundamental source of energy that is instrumental in our climate system it would be reasonable to assume that changes in the sun's energy output would cause the climate to change. 
Current global warming however cannot be explained by solar variations. Some examples are evidenced such as since 1750, the average amount of energy coming from the Sun either remained constant or increased slightly. If global warming was caused by a more active sun, then scientists would expect to see warmer temperatures in all layers of the atmosphere. They have only observed a cooling in the upper atmosphere, a warming at the surface and in the lower parts of the atmosphere. This is due to greenhouse gasses capturing heat in the lower atmosphere. Also climate models that include solar irradiance changes cannot reproduce last century's observed temperature trend without including a rise in greenhouse gases.

\section{MAN MADE CAUSES OF CLIMATE CHANGE}

The climate is changing due to man-made greenhouse gases. We are already committed to future substantial change over the next 30 years and change is likely to accelerate over the rest of the 21st century.

The Industrial Revolution in the 19th century saw the large-scale use of fossil fuels for industrial activities. Fossil fuels such as oil, coal and natural gas supply most of the energy needed to run vehicles, generate electricity for industries and households. The energy sector is responsible for about $3 / 4$ of the carbon dioxide emissions, $1 / 5$ of the methane emissions and a large quantity of nitrous oxide.

Carbon dioxide is undoubtedly, the most important greenhouse gas in the atmosphere. Changes in land use pattern, deforestation, land clearing, agriculture, and other activities have all led to a rise in the emission of carbon dioxide. Methane is another important greenhouse gas in the atmosphere. It is released from animals such as dairy cows, goats, pigs, buffaloes, camels, horses and sheep. Methane is also emitted during the process of oil drilling, coal mining, leaking gas pipelines, landfills and waste dumps.

The certainty of global warming can be seen through some of the natural phenomenon like the effect on crops and extreme weather conditions around the world. It is especially clear in the dramatic change of the polar caps, i.e. the Arctic ice cap is shrinking and the Antarctica ice shelf is melting. There other elements of people's homes that contribute to climate change indirectly. Everything, from furniture to computers, from clothes to carpets, all use energy when it is produced and transported - and this causes carbon emissions to be released. The three main causes of the increase in greenhouse gases observed over the past 250 years have been fossil fuels, land use, and agriculture. Agriculture has been shown to produce significant effects on climate change, primarily through the production and release of greenhouse gases such as carbon dioxide, methane, and nitrous oxide.

Another contributing cause of climate change is when agriculture alters the Earth's land cover, which can change its ability to absorb or reflect heat and light. Land use change such as deforestation and desertification, together with use of fossil fuels, are the major anthropogenic sources of carbon dioxide.

Deforestation is another major contributor to the Climate change. Rainforests are precious resource in our world. They form part of a delicate ecosystem that has taken millions of years to evolve. Rainforests every year help to absorb almost $20 \%$ of manmade $\mathrm{CO}_{2}$ emissions therefore deforestation can be classed as a major contributor to the causes of climate change. Cutting down rainforests faster than they can be replaced has a devastating effect on the carbon emission cycle producing an extra $17 \%$ of greenhouse gases.

Forests reduce greenhouse gas emissions to combat global warming. $20 \%$ of global greenhouse gas emissions result from deforestation and degradation of forest, more than all the world's cars, trucks, ships and planes combined. Fossil fuels release carbon dioxide into the atmosphere contributing to global warming and climate change. Forest alleviates this change by converting carbon dioxide to carbon during photosynthesis. The world's forests contain about 125 percent of the carbon found in the 
atmosphere. This carbon is stored in the form of wood and vegetation through "carbon sequestration". The atmospheric carbon dioxide concentration in the pre-industrial era was $280 \mathrm{ppm}$. Now the level has risen to $375 \mathrm{ppm}$, a $30 \%$ increase. It is predicted that the level will be $450 \mathrm{ppm}$ in 2050 resulting in 1.8 to $3^{\circ} \mathrm{C}$ increase in temperature eventually. Therefore, global warming will produce a sharp upswing followed by a deep plunge into a glacial period several thousand years from now. A potential impacts such as increased cyclone intensity; melting of polar iceberg and glaciers; increased salinity and changes in oceanic currents sea level rise and inundation of low lying cities. Coral bleaching and mortality of coral reef; colonization of invasive species and species migration; changes in ecosystem; mass extinction; ozone layer depletion; water shortage; and spreading of diseases - is predicted. "

\section{THE PHYSICS OF CLIMATE CHANGE}

Weather and climate are driven by the absorption of solar radiation and the subsequent re-distribution of that energy through radiative, advective, and hydrological processes. The average temperature of the Earth is essentially determined by the balance between incoming solar radiation and outgoing " heat' ' radiation. A change in this radiative balance is termed a radiative forcing, which is measured in Watts per square meter.

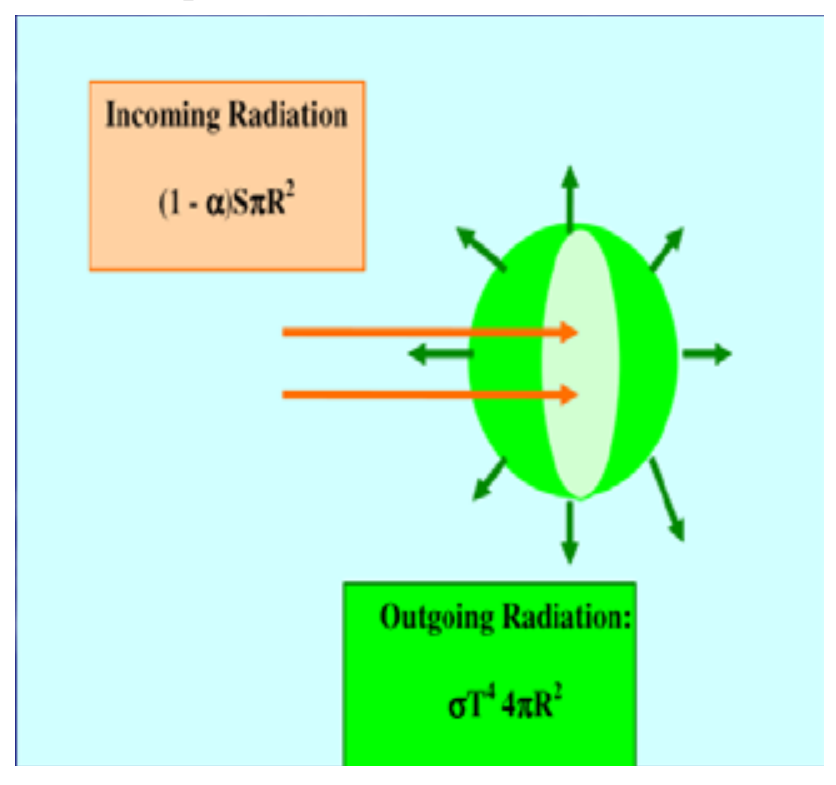

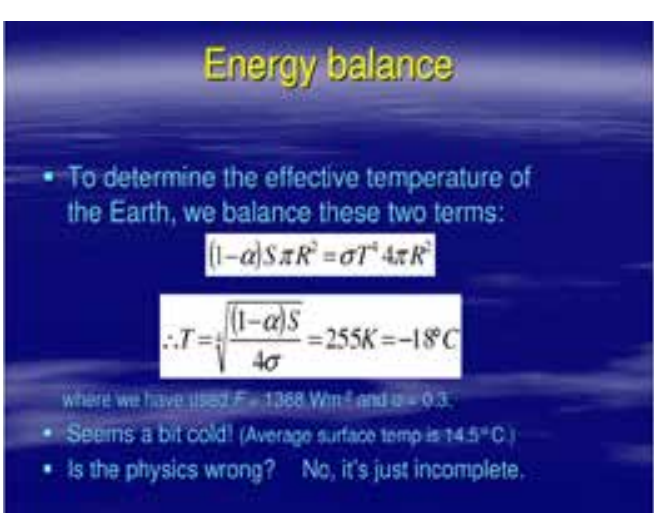

This template shows that the average temperature on the top of atmosphere is very cold and that at the surface is a bit cold. A modification is introduced for surface temperature using following relations.

Energy balance at the surface, and at the top of atmosphere, gives

On solving these two equations, we obtain;

$\mathrm{Ta}=255 \mathrm{~K}$ and $\mathrm{Tg}=300 \mathrm{~K}$

This time it is a little too warm, but it is an improvement.

Water vapour is a 'feedback' for greenhouse gases. $\mathrm{CO}_{2}, \mathrm{CH}_{4}, \mathrm{O}_{3}$ etc are forcing' agents. They stay in the atmosphere whatever and 'force' more heat into the climate system. This effect is measured by 'Radiative forcing constant'. More $\mathrm{CO}_{2}$ means more warmth which causes more $\mathrm{H}_{2} \mathrm{O}$ to be evaporated. Water vapour goes in and out of the atmosphere very quickly. Carbon dioxide is there for $\sim 100$ years. That makes a very big difference in the way they act.

It doesn't matter how much water vapour is in the atmosphere, adding $\mathrm{CO}_{2}$ and $\mathrm{CH}_{4}$ will absorb more IR because they absorb different parts of the IR radiation spectrum. $\mathrm{H}_{2} \mathrm{O}$ and $\mathrm{CO}_{2}$ molecules and other Greenhouse Gases(GHGs) are susceptible to take on energy, especially in IR range of EMR which they radiate re- radiate in random directions. So some goes back down to Earth giving rise to the Greenhouse effect.

According to Intergovernmental Panel on Climate Change(IPCC),"The radiative forcing of the surfacetroposphere system due to the perturbation in or the introduction of an agent (say, a change in greenhouse gas concentrations) is the change in net (down minus up) irradiance (solar plus long-wave; in $\mathrm{Wm}^{-2}$ ) at 
the tropopause AFTER allowing for stratospheric temperatures to readjust to radiative equilibrium, but with surface and tropospheric temperatures and state heldfixedattheunperturbedvalues".(IPCC)Itmeansthe extra heat flowing into (or out of) the climate system as a result of a change in some part of the system. (in $\mathrm{W} / \mathrm{m}^{2}$ ).

The gases in the atmosphere absorb, and then reradiate some parts of the spectrum but not others. The structure of the molecule determines what sort of energy is absorbed. Oxygen and Nitrogen molecules respond to high energy EMR in UV region.

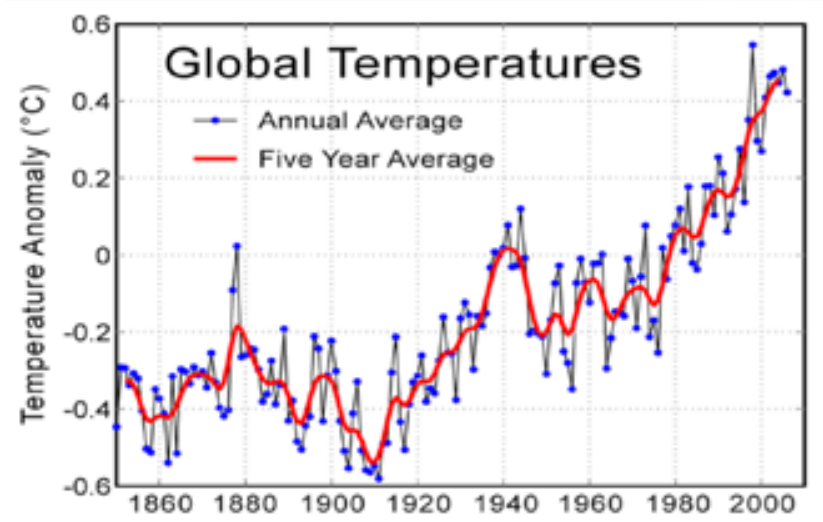

This graph shows the temperature variations for past 140 years. It shows how temperature is rapidly increasing in past 40 years.

The relationships between the atmospheric concentration of greenhouse gases and their radiative effects are well quantified. Forcing from the longlived greenhouse gases: carbon dioxide, methane, and nitrous oxide, is presently about 2.5 Watts per meter squared $\left(\mathrm{W} / \mathrm{m}^{2}\right)$. Of this total, $1.6 \mathrm{~W} / \mathrm{m}^{2}$ is from carbon dioxide alone. The total anthropogenic forcing is uncertain, particularly because the magnitude of the negative forcing associated with sulfate aerosols is unclear. While changes in solar irradiance may have affected global climate in the last century, a $0.15 \%$ change irradiance, the order of estimated changes, results in only a $0.36 \mathrm{~W} / \mathrm{m}^{2}$ forcing.

There are still significant uncertainties in moving from greenhouse gas emissions, particularly those of carbon dioxide, to atmospheric concentrations. The largest source of uncertainty lies in determining the magnitude of climate feedbacks. For example, an increase in trapped radiation and the associated warming is expected to increase the level of water vapor in the atmosphere, which would tend to further enhance the greenhouse effect, a positive feedback. A negative feedback would be an increase in clouds that reflected more sunlight back into space. The actual feedback from changes in clouds is uncertain since they also act to trap outgoing infrared radiation.

It is the balance between positive and negative feedbacks which will determine the net effect of increased greenhouse gases. While climate models agree that the net effect will be warming, the amount of warming (and other changes) given by various models is different. The current central warming estimate, developed by the Intergovernmental Panel on Climate Change (IPCC), is a global average temperature rise of two degrees centigrade by the year $2100 \mathrm{AD}$.

\section{CONCLUSIONS}

With the increase in economic and population growth the increase in use of energy is inevitable which is the primary source of greenhouse gases. One of the largest uncertainties in future greenhouse emissions is the effect of technological change. If renewable energy sources become cost-effective, if there are major gains in the efficiency of energy utilization, or if there is a large increase in the use of nuclear energy (fission or fusion), then emissions of greenhouse gases may be substantially restrained

The degree to which the climate will change in the future is still uncertain. However climate change may lead to significant damage to both human and natural systems.

\section{REFERENCES:}

1. Wikipedia free encyclopedia

2. Journal of Atmospheric Chemistry and Physics, 7, 2287-2312, 2007

3. www.climatechangechallange.org/Resource Centre/Climate_Change

4. http://www.ipcc.ch/presentations_and_ speeches/presentations_and_speeches.shtml

5. http://www.aps.org/policy/reports/popareports/energy/climate.cfm 